\title{
The Correlation between Motivation, Academic Performance, Socio-economic Status and the English Academic Performance of EFL College Students from Urban and Non-urban Areas in China
}

\author{
Zheng Ding-yao \\ Department of Foreign Languages, Baise University, China \\ Received July 9, 2020; Revised August 31, 2020; Accepted September 11, 2020
}

\begin{abstract}
Cite This Paper in the following Citation Styles
(a): [1] Zheng Ding-yao, "The Correlation between Motivation, Academic Performance, Socio-economic Status and the English Academic Performance of EFL College Students from Urban and Non-urban Areas in China," Linguistics and Literature Studies, Vol. 8, No. 5, pp. 269 - 275, 2020. DOI: 10.13189/lls.2020.080506.
\end{abstract}

(b): Zheng Ding-yao (2020). The Correlation between Motivation, Academic Performance, Socio-economic Status and the English Academic Performance of EFL College Students from Urban and Non-urban Areas in China. Linguistics and Literature Studies, 8(5), 269 - 275. DOI: 10.13189/lls.2020.080506.

Copyright $\mathrm{C} 2020$ by authors, all rights reserved. Authors agree that this article remains permanently open access under the terms of the Creative Commons Attribution License 4.0 International License

\begin{abstract}
The main aim of this study was to examine the correlation of influential English learning factors and English academic performance of EFL college students from urban and non-urban areas. Three possible influential factors examined were student's motivation, academic performance and socio-economic status. The subjects were 126 students from Nanning labeled as UAS (Urban Area Students) and 136 students from non-urban areas labeled as NUS (Non-Urban Students) respectively. A questionnaire was used to investigate the subject's motivation and their parents' socio-economic status. The main result of the study was that both English academic performance of UAS and that of NUS were more related to motivation than other factors. The correlation between factors was further analyzed. The results of socio-economic status were divided into two main groups: economic and cultural socio-economic status. Both groups were directly proportional to the English academic performance of UAS and that of NUS. The result showed that the English performance of UAS was more related to economic socio-economic status; however, that of NUS was more related to cultural socio-economic status. On the basis of the results, among all factors, motivation is the most influential for students' English achievement. The influences of motivation on English learning are significantly different in both groups. Socio-economic
\end{abstract}

status is highly correlated to students' English achievement in China. The results also show socio-economic and cultural advantages for students are highly significant for English learning. Thus, teachers should provide more socially and culturally advantageous environment for students from low socio-economic status families. The result that urban and non-urban students' English academic performance correlated to different types of status may imply that parents in urban and non-urban area may hold different beliefs toward English learning. Further study could be done to explore such differences.

Keywords Socio-economic Status, EFL, College, English Learning

\section{Introduction}

As China has become more globalized, English has become one of the most important indicators of a student's competitiveness. Better English proficiency means better opportunities for students in China. Consequently, students' English proficiency in colleges has been the school's evaluation focus for many years. The Ministry of Education has also funded school's plans for promoting 
students' English competence. However, some schools' plans seemly have not appeared to be able to contribute to the advancement of student's English ability.

In order to help students' English learning, some influential factors must be identified and thus teachers will be able to help students more easily and efficiently. Many studies contributed to the identification of influential learning factors and a number of these studies indicate that factors, such as motivation and socio-economic status are powerful indicators of a student's successful learning [9]. On the basis of identifying these factors, teachers could provide more assistance to those disadvantaged students. Generally speaking, the influential learning factors are placed into two categories: intellectual factors and non-intellectual factors [1]. Among intellectual factors, students' motivation is regarded as one of the most of powerful predicators for students' learning results. In other words, most successful learners are highly motivated. The second factor chosen in this study is students' academic performance. Is the students' academic performance in school a strong predicator for their English learning? In the case of a student's English performance being strongly predicated by their academic performance, we could put more emphasis on those low academic performance students. Another factor is student's socio-economic status, chosen as the non-intellectual factors. Many studies show that some students have started learning English long before their classmates [6]. The factor underlying the young English learners could be their parents' socio-economic status. These early learners usually possess higher socio-economic status, and the students' learning attitudes could possibly be influenced by their parents. Therefore, the socio-economic status is also included in the study.

Considering all these factors, the study aims to investigate the relationship between students' motivation, academic performance and socio-economic status.

Finally, another important learning factor is students' residential area. Recent studies [3] state that the discrepancy of urban and non-urban development also contributes to different English learning results. After analyzing the students' achievement, the binomial distribution and the discrepancy of urban and rural students' learning results have been found [2]. These findings have initiated more studies to investigate the English phenomena further in China. Hence, subjects' residential area is also listed as a variable. Students in urban area are labeled as UAS (Urban Area Students) and students in non-urban, labeled as NUS (Non-Urban Students) in this study.

\section{Objective}

As mentioned above, the aim of this study was to examine the correlation between influential English learning factors and English academic performance of EFL students from urban and non-urban areas. Three possible influential factors examined were student's motivation, academic performance and parent's socio-economic status. The objectives of the study are as follows:

1. To identify the correlation between UAS's English achievement performance, academic achievement, motivation and socio-economic status.

2. To understand the correlation between NUS's English achievement performance, academic achievement, motivation and socio-economic status.

3. To understand the differences between UAS and NUS's English learning factors.

\section{Literature Review}

\section{Socio-Economic status}

Several studies show that socio-economic status is one of the influential factors to student's learning results [10]. It mainly influences students in two ways. First, students from a high socioeconomic family could possibly have a more advantageous environment for learning. For example, books or teaching materials are more easily accessible in high socioeconomic level families. Boyers has stated that students most at risk are those learners are mostly students who come from low-income families [8].

Second, students could be deeply influenced by their parents' values and beliefs towards learning. Students from high culture socio-economic status family could hold the belief that the success of a person depends upon how educated a person is rather than how much money they make [8].

Based on these two types of influences that socio-economic status brings to students, in this study the parents' socio-economic status is placed into two categories: Economic socio-economic status, by which we mean that socio-economic status is determined by the incomes of the family; the cultural socio-economic status puts more emphasis on the occupations of student's parents.

\section{Motivation}

Doiz defines motivation as an inner drive, impulse, emotion, or desire that moves one to a particular action or, in more technical terms, motivation refers to the choices people make as to what experiences or goals they will avoid or approach. And the degree of effort they will exert in this respect [4]. The motivation questionnaire used in the study is based upon the to Doiz's motivation questionnaire [5].

One of the best -known and historically most significant studies of motivation in second language learning was carried out by Robert Gardner and Wallace Lambert [7]. Over a period of 12 years they extensively studied foreign 
language learners in Canada, several parts of the United States, and the Philippines in an effort to determine how attitudinal and motivational factors affect language learning success. Motivation was examined as a factor of a number of different kinds of attitudes. Two different clusters of attitudes divided two basic types of motivation: instrumental motivation and integrative motivation. Instrumental motivation refers to motivation to acquire a language as a means of attaining instrumental goals: furthering a career, reading technical materials, translation, and so forth. An integrative motivation is employed when learners wish to integrate themselves within the culture of the second language group, to identify themselves with, and become a part of that society. Many of Lambert's studies and one study by Spolsky [7] found that integrative motivation generally accompanies higher scores on proficiency tests in a foreign language. The conclusion from these studies was that integrative motivation may indeed be an important requirement for successful language learning. Yet another and perhaps the most powerful dimension of the whole motivation construct is the degree to which learners are intrinsically or goal-orientedly motivated to succeed in a task. In this present study, the student's motivation was measured from a questionnaire which covered both intrinsic and goal-oriented motivation [12].

\section{Method}

For the purposes of this study, two measure instruments were needed: a. English achievement test for our subjects. b. a questionnaire for student's motivation and. socio-economic status.

\section{A. English achievement test}

A copy of English achievement test was designed to measure students' English academic performance. The test items, including listening and reading, were all from the content of subjects' textbooks. Content validity was employed to ensure its effectiveness. The test-retest reliability coefficient was .8 , which shows its acceptable stability.

B. A questionnaire for student's motivation and socio-economic status

A questionnaire was employed to serve as the instrument to measure students' motivation and to identify students' socio-economic status. The questionnaire covered two parts. The first part was designed to collect students' basic background data such as, gender, region, family income, parents' occupations and so forth. The second part was the inventory for measuring students' motivation. The questionnaire was revised and translated into Chinese from Gardner and Lambert's Inventory [11].

Students were later placed into two categories of socio-economic status, according to their family incomes and parent's occupations.

\section{Subjects}

The subjects were 126 students from Nanning labeled as UAS (Urban Area Students) and 136 students from non-urban areas (Tiendong County, Hechi County and Chongzuo County) labeled as NUS (Non-urban Students). In addition, all subjects' academic performance and English academic performance were also collected.

A control group was chosen from freshmen majoring in English. UAS and NUS used the same version of the textbooks.

In 2019, second semester, the English achievement test was administered to the subjects and all subjects were asked to complete the questionnaire regarding their English motivation and parents' socio-economic status.

\section{Data Analysis}

The SPSS (Statistical Packages for the Social Sciences) Version 20.0 for Windows was used to run descriptive statistics and the correlation test to answer the research questions.

Descriptive statistics of English achievement and two tailed independent T-test for UAS and NUS were also computed and compared to show the differences between two groups.

\section{Results}

The study aims to compare and contrast the different English learning factors between the UAS and NUS learners in China. The findings are divided into four parts. Comparison of the UAS and NUS's English achievement tests is included in the first part. In the second part, the urban area's correlation of English achievement, academic achievement, socio-economic status and motivation is discussed, and the results of the non-urban area are illustrated in the third part. The results of urban and non-urban area are compared and contrasted in the last part.

\section{Comparison of English achievement tests}

An English achievement test was employed to determine the differences between the UAS and NUS's English learning results. The mean of the UAS is 84.2 , which is slightly higher than that of the NUS, 80.25 (Table 1). Levene's Test for Equality of Variances was run and indicated that both groups were not significantly discrete $(\mathrm{F}$ $=.758, p=.425>.05)$. Therefore, the English achievement tests of UAS and NUS are not considered to be significantly different (Table 2). This means two groups of students were homogeneous. 
The Correlation between Motivation, Academic Performance, Socio-economic Status and the English Academic Performance of EFL College Students from Urban and Non-urban Areas in China

Table 1. Descriptive Statistic of English Achievement

\begin{tabular}{cccccc}
\hline & Area & N & Mean & SD & SD E. \\
\hline \multirow{2}{*}{ English Achievement } & Urban & 126 & 84.20 & 4.98 & 1.58 \\
& Non-urban & 136 & 80.25 & 3.85 & 1.36 \\
\hline
\end{tabular}

Table 2. Independent T-test of English Achievement Test

\begin{tabular}{|c|c|c|c|c|c|c|c|c|c|c|}
\hline & & \multicolumn{9}{|c|}{ Levene's } \\
\hline & & \multirow[b]{2}{*}{$\mathbf{F}$} & \multirow[b]{2}{*}{ Sig } & \multirow[b]{2}{*}{$\mathbf{t}$} & \multirow[b]{2}{*}{ DF } & \multirow[b]{2}{*}{ Sig(two-tailed) } & \multirow[b]{2}{*}{ SD } & \multicolumn{3}{|c|}{$95 \%$ confident interval } \\
\hline & & & & & & & & SE & low & upper \\
\hline English & $\begin{array}{c}\text { Equal } \\
\text { variance }\end{array}$ & .758 & .425 & 1.842 & 260 & .097 & 3.95 & 2.14 & -.62 & 8.67 \\
\hline Achievement & $\begin{array}{l}\text { Unequal } \\
\text { variance }\end{array}$ & & & 1.898 & 15.992 & .123 & 3.95 & 2.08 & -.49 & 8.46 \\
\hline
\end{tabular}

Table 3. Correlation Matrix of UAS

\begin{tabular}{|c|c|c|c|c|c|c|c|}
\hline & & & $\begin{array}{c}\text { English } \\
\text { Achievement }\end{array}$ & $\begin{array}{c}\text { Academic } \\
\text { achievement }\end{array}$ & $\begin{array}{c}\text { Economi } \\
\text { c socio }\end{array}$ & $\begin{array}{c}\text { Culture } \\
\text { socio }\end{array}$ & Motive \\
\hline \multirow[t]{15}{*}{ Spearman's rho } & $\begin{array}{c}\text { English } \\
\text { achievement }\end{array}$ & Coefficient & 1.00 & .658 & $.752 *$ & $.768 *$ & $.823 *$ \\
\hline & & Sig & . & .121 & .042 & .039 & .032 \\
\hline & & $\mathrm{N}$ & 126 & 126 & 126 & 126 & 126 \\
\hline & $\begin{array}{c}\text { Academic } \\
\text { achievement }\end{array}$ & Coefficient & .658 & 1.00 & .678 & $.717^{*}$ & $.787 *$ \\
\hline & & Sig & .121 & . & .048 & .049 & .032 \\
\hline & & $\mathrm{N}$ & 126 & 126 & 126 & 126 & 126 \\
\hline & Economic socio & Coefficient & $.752 *$ & .678 & 1.00 & $.875 *$ & $.720 *$ \\
\hline & & Sig & .042 & .048 & . & .012 & .120 \\
\hline & & $\mathrm{N}$ & 126 & 126 & 126 & 126 & 126 \\
\hline & Culture socio & Coefficient & $.768 *$ & $.717^{*}$ & $.875^{*}$ & 1.00 & .690 \\
\hline & & Sig & .039 & .049 & .012 & . & .251 \\
\hline & & $\mathrm{N}$ & 126 & 126 & 126 & 126 & 126 \\
\hline & Motive & Coefficient & $.823 *$ & $.787 *$ & $.720 *$ & .690 & 1.00 \\
\hline & & Sig & .032 & .032 & .120 & .251 & . \\
\hline & & $\mathrm{N}$ & 126 & 126 & 126 & 126 & 126 \\
\hline
\end{tabular}

${ }^{*} p<.05$ (two-tailed)

\section{Correlation of UAS}

The correlation coefficient of English and academic achievement is .658. Both types of socio-economic status are significantly correlated to English achievement (respectively, economic group, .752, $p<.05$; cultural group, .768, $p<.05$ ). The correlation coefficient of the motivation and English achievement also indicates significant correlation. Motivation and two kinds of socio-economic status are highly correlated to English achievement in young English learners in urban areas. However, academic achievement is not significantly correlated to English achievement (Table 3).

\section{Correlation of NUS}

The correlation coefficient of English and academic achievement is .725. The coefficient of economic socio-economic status is .524 ; while that of cultural socio-economic status is $.851(p<.05)$. In the two types of socio-economic status, only cultural one reaches significant level. The correlation coefficient of motivation and English achievement is also significantly correlated ( $p$ $<.05$, .792). Academic achievement, cultural socio-economic status and motivation are highly correlated to English achievement in students from non-urban areas. However, the economic socio-economic status is not significantly correlated to English achievement (Table 4). High correlation between cultural socio-economic and English achievement means students from high cultural socio-economic status families could possibly have high English achievement test scores. 
Table 4. Correlation Matrix of NUS

\begin{tabular}{|c|c|c|c|c|c|c|c|}
\hline & & & $\begin{array}{c}\text { English } \\
\text { Achievement } \\
\end{array}$ & $\begin{array}{c}\text { Academic } \\
\text { achievement }\end{array}$ & $\begin{array}{c}\begin{array}{c}\text { Economic } \\
\text { socio }\end{array} \\
\end{array}$ & $\begin{array}{c}\text { Culture } \\
\text { socio }\end{array}$ & Motive \\
\hline \multirow[t]{15}{*}{ Spearman's rho } & $\begin{array}{c}\text { English } \\
\text { achievement }\end{array}$ & Coefficient & 1.00 & $.725^{*}$ & .524 & $.851^{*}$ & $.792 *$ \\
\hline & & Sig & . & .038 & .041 & .022 & .029 \\
\hline & & $\mathrm{N}$ & 136 & 136 & 136 & 136 & 136 \\
\hline & $\begin{array}{c}\text { Academic } \\
\text { achievement }\end{array}$ & Coefficient & $.725^{*}$ & 1.00 & .556 & $.881^{*}$ & $.782 *$ \\
\hline & & Sig & .038 & . & .475 & .021 & .031 \\
\hline & & $\mathrm{N}$ & 136 & 136 & 136 & 136 & 136 \\
\hline & Economic socio & Coefficient & .524 & .556 & 1.00 & .470 & .420 \\
\hline & & Sig & .410 & .475 & . & .425 & .389 \\
\hline & & $\mathrm{N}$ & 136 & 136 & 136 & 136 & 136 \\
\hline & Culture socio & Coefficient & $.851^{*}$ & $.881 *$ & .470 & 1.00 & $.762 *$ \\
\hline & & Sig & .022 & .021 & .425 & . & .370 \\
\hline & & $\mathrm{N}$ & 136 & 136 & 136 & 136 & 136 \\
\hline & Motive & Coefficient & $.792 *$ & $.782 *$ & .420 & $.762 *$ & 1.00 \\
\hline & & Sig & .029 & .031 & .389 & .037 & . \\
\hline & & $\mathrm{N}$ & 136 & 136 & 136 & 136 & 136 \\
\hline
\end{tabular}

$* p<.05$ (two-tailed)

\section{Comparison of Two Matrixes}

After cross-examining two correlation matrixes, the findings are presented and illustrated as follows.

a. Among all factors, motivation is the most influential for student's English achievement. The influences of motivation on English learning are significantly different in both groups.

b. Socio-economic status is a highly correlated to student's English achievement in China. Cultural socio-economic status is more related to student's English learning results than economic socio-economic status, especially in NUS; therefore, the cultural socioeconomic is more important to non-urban students' English achievement. Therefore, in non-urban areas, the students' English achievement is more associated with cultural socio-economic status.

c. The correlation of students' academic achievement to English achievement varies depending on the students' residential area. For example, the academic achievement of students from non-urban areas is significantly correlated to their English achievement (NUS correlation coefficient of academic achievement and English achievement is $.725^{*}$.). In contrast, the correlation of English achievement to academic achievement of students from urban areas is lower (Coefficient is .658)

\section{Discussion}

\section{The differences between urban and non-urban area}

In this study, some of the differences between urban between non-urban areas English learners are found. First, academic achievement is more correlated to English in non-urban areas. This means that English performance could be more easily predicted in non-urban areas. It makes sense that if a student performs academically well in all other subjects, presumably he could possibly have a higher English achievement. However, in urban areas, academic achievement seems not to be a very strong predictor of English achievement. This implies that students having good academic performance do not necessarily have good English achievement. This phenomenon could be the result of the parent's beliefs towards English learning. In the city area, more parents hold the beliefs that the earlier the students learn English, the better their English will be. Thus, some parents may send their children to a bilingual school to learn English while they are still in kindergarten. Also, more students may have had experience of living in a foreign county due to the needs of their parents' jobs. English is not a new subject to those "early starter" students; therefore, they have an advantage in English learning. In contrast, those who have high academic performance didn't necessarily begin to learn English earlier than others. This assumption could be further confirmed by the discrepancy between urban and non-urban area's correlation of academic achievement and English achievement.

In Hechi County, the students who start to learn English 
before junior high school are fewer than their contemporary peers in Nanning. In other words, most students in non-urban area start to learn their English when they are junior high school students. There are fewer "advantaged" learners in the same class. English is just another subject learned in school. Most students haven't learned English until they're in junior high school; therefore, the correlation of academic performance and English achievement in Hechi County is higher.

\section{Economic socio-economic status vs. cultural socio-economic status}

Usually socio-economic status is identified by "income". As the students could also possibly be influenced by their parent's value towards education. Income could not be the only index for socio-economic status. Some parents with high income don't necessarily support their students' education. Taking teachers as an example, "teachers" may not have high income; however, most of them support an education system. Teachers' belief that education is very important to their students may consciously or unconsciously be acquired by their children. Results in the study correspond to our general impression that teachers' children usually achieve good grades in school.

In contrast, parents with high economic socio-economic status may not be so supportive of their students' education. Basically, those high economic socio-economic status parents don't earn their high income through their educational background. They could be higher- level farmers, land-owners, brokers, whole sale agent, etc. Education seems not to be so financially related to their income.

However, these two types of socio-economic status are correlated to themselves. Interestingly, in urban areas these two types of socio-economic status have higher correlation than in non-urban area. This shows that the more education a person has, the higher income he may have in urban areas. The correlation between economic socio-economic status and cultural status is lower in non-urban area. This phenomenon is further confirmed by the economic situation in non-urban area, such as Tiandong County, Henchi County. A great number of people with high socio-economic status are involved agriculture or manufacturing. They may have a high income, but they do not totally believe in education.

Based on this discussion, three main conclusions can be summarized. First, motivation is highly correlated to students' English learning in urban or non-urban areas. Second, students' English learning results are differently associated to economic and cultural socio-economic status. In urban areas, economic socio-economic status is more important to student's English learning; however, from non-urban area, cultural socio-economic status is more important. Finally, compared to urban areas, academic achievement is a stronger predictor of English learning in non-urban area.

\section{Limitations}

The main limitation of this study is that regression analysis should be administered to the results. By analyzing the regression of the English learning factors, the factor's contribution coefficient could possibly be determined. Second, the size of the subjects is mainly limited to 262 (126 and 136), and replication of the study is necessary to ensure the findings are applicable to students in other contexts.

\section{REFERENCES}

[1] Benjamin, A. (n.d.). Factors Influencing Learning. Noba. https://nobaproject.com/modules/factors-influencing-learni ng

[2] Chang, S. M. (2005). The study of English learning of elementary school student in urban and rural Areas. National Xinzhu University of Education, Xinzhu, Taiwan.

[3] Chang, W. C., Zhou, Z. T., Chen, C. Y., Ye, X. N., Lin, C. C., \& Hsu, Y. G. (Eds.). (2004). Final report of bimodal distribution of basic competence test for junior high school students and the improvement strategies. Taipei: Ministry of Education.

[4] Carreira, J. M. (2006). Motivation for learning English as a foreign language in Japanese elementary schools. JALT Journal, 28(2), 135-158. https://jalt-publications.org/sites/d efault/files/pdf-article/jj-28.2-art2.pdf

[5] Doiz, A. \& Lasagabaster, D. (2018). Teachers' and students' second language motivational self system in English-medium instruction: a qualitative approach. TESOL Quarterly, 52(3), 657-679. https://doi.org/10.1002/tesq.452

[6] Dornyei, Z., \& Ushioda, E. (2017). Teaching and Researching Motivation (2nd ed.). London: Longman. https://doi.org/10.4324/9781315833750

[7] Gardner, R. C. (1985). The Role of Attitudes and Motivation. In W. E. Lambert (Ed.), Social Psychology and Second Language Learning (pp. 345-389). London: Edward Arnold.

[8] Goddard, R. D., Sweetland, S. R., \& Hoy, W. K. (2000). Academic emphasis of urban technological and vocational schools and student achievement in reading and mathematics: A multilevel analysis. Educational Administration Quarterly, 36(5), 683-703. https://doi.org/1 $0.1177 / 00131610021969164$

[9] Kaffemanienè, I., Masiliauskienè, E., Melienè, R., \& Milteniené, L. (2017). Educational environment of the modern school in the aspects of learning factors, school climate and education paradigms. Pedagogika, 126(2), 6282. https://doi.org/10.15823/p.2017.20

[10] Muawanah, R. C. (2019). The Association Between Socio-Economic Status and Child Development: A Study Among Preschool-Age Children in The Slum Area of 
Jakarta and Bekas. Int. J. Environ. Res. Public Health, 16(5), 655-657. https://doi.org/10.3390/ijerph16050677

[11] Sharma, R. (2012). Kuppuswamy's Socioeconomic Status Scale - Revision for 2011 and Formula for Real-Time Updating. Indian Journal of Pediatrics, 79, 961-962. https://doi.org/10.1007/s12098-012-0735-7.

[12] Yu, Yu. (2013). A Study of Learning Motivation and Learning Satisfaction of the Junior High Supplement School Students in Taichung City. Zhongtai University of Technology, Taiwan. 